Differential impact of web habits and active navigation on adolescents' online learning

Costanza De Simone ${ }^{* 1,2}$, Antonella Battisti ${ }^{3,4}$, and Azzurra Ruggeri ${ }^{1,2}$

${ }^{1} M P R G$ iSearch, Max Planck Institute for Human Development, Lentzealle 94, Berlin 14195, Germany

${ }^{2}$ School of Education, Technical University Munich, Marsstraße 20-22, 80335 Munich, Germany

${ }^{3}$ IIS Buontalenti-Cappellini-Orlando, via Emilio Zola 6/b, 57122 Livorno, Italy ${ }^{4}$ NEST, Istituto Nanoscienze - CNR and Scuola Normale Superiore, Piazza San Silvestro 12, 56127 Pisa, Italy

\footnotetext{
Author Note

The authors have no conflict of interests to declare.

${ }^{*}$ Correspondence should be addressed to Costanza De Simone, MPRS iSearch, Max Planck Institute for Human Development, Lentzeallee, 94, 14195 Berlin, Germany. Email: desimone@mpib-berlin.mpg.de ( (D) https://orcid.org/0000-0002-0239-7238).
} 


\title{
ADOLESCENTS ONLINE ACTIVE LEARNING
}

\begin{abstract}
In this study we investigated how 14- to 17 -year-olds $(n=48)$ search the web for information about unsettled scientific dilemmas. In particular, we addressed to what extent adolescents' capability to appraise accurate web sources, learn, and mold informed opinions is influenced by the quality of their online search strategies, the control they exert over the online search experience, and the experience they have while searching the web for relevant factual information. Our results show that adolescents' learning resulting from independent online search was not influenced by their search strategies and was generally quite poor, although they did identify and consult the most relevant and informative web sources. Interestingly, we found that having active control over the search process enhanced participants' learning and retention of factual information, but following the search process more passively increased their capability to reflect on, process, and elaborate on the information found on the web. This latter aspect was also positively influenced by having greater experience searching the web to perform school assignments. Taken together, these findings can inform educational practices, supporting the development and implementation of more effective interventions to empower the conscientious use and successful mastery of the pseudo-infinite information available on the web.
\end{abstract}

Keywords: Information literacy, Online search, Active learning, Adolescents, Media in education 


\section{Differential impact of web habits and active navigation on adolescents' online learning}

\section{Introduction}

It is crucial for us - humans of the information age - to be able to critically reflect on the insights and opinions we gather, or often just get bombarded with, from our social and digital environment: A friend might share a post on Facebook warning us not to use deodorants anymore because they allegedly contain carcinogenic aluminum compounds, or we may come across an advertisement trying to convince us to buy this new kind of mineral water that contains a lower concentration of carcinogenic substances, such as nitrates. Whether information comes from real-world encounters, social media feeds, the news on TV, or Google, we are constantly faced with the challenge of evaluating its accuracy. In this sense, the web is an extremely powerful resource; searching it allows us to understand, learn, and form opinions about health, scientific, political, or social issues we know little or even nothing about (Corley et al., 2011). The increasing involvement of institutions and scientists on all kinds of web and media platforms (e.g., Facebook and YouTube) contributes to this empowerment by facilitating the spread and accessibility of complex findings to a general audience and enabling people to be actively engaged by commenting and sharing opinions (Brossard, 2013).

Because of the ease, immediacy, and success with which one can obtain information, searching the web has become a daily routine to gain knowledge on a variety of topics, ranging from food safety (Bouzembrak et al., 2019) to science (National Science Board., 2012). Seven out of ten European aged 16- to 29 ranked searching for information among the most pursued activities on the web, together with emailing, video browsing, and using social networks (Eurostat, 2020). At least $80 \%$ of web users claim to prefer this method to alternative offline sources (Jiménez-Pernett et al., 2010), and a large majority of Americans (81\%) report they rely on their own web research over friends and family (43\%) or professional experts $(31 \%)$ when gathering information before making an important 
decision (Rainie et al., 2019).

The web represents an appealing learning resource especially for adolescents. First, they are generally more responsive than adults to interactive and innovative approaches to knowledge acquisition (Skopelja et al., 2008). Second, adolescence is a major stage of development characterized by a strong desire for autonomy and self-determination (Shifflet-Chila et al., 2016). In this context, the internet represents a powerful tool that allows adolescents to explore freely and independently, searching for information they might be too embarrassed to ask their peers or parents to supply, and to experiment with different roles to achieve a sense of occupational and sexual identity. Indeed, a survey by the EU Kids Online Network indicated that $81 \%$ of 15 - to 17 -year-old students go online daily after school, surfing on average for 3 hours (Smahel et al., 2020), and according to a survey by the Pew Internet and American Life Project, $83 \%$ of children of the same age believe that the internet has enormous potential to improve their study habits and schoolwork, as it helps them quickly find answers, communicate with friends, and satisfy their curiosity (Lenhart et al., 2007).

Yet, having every kind of information available at our fingertips does not necessarily make information acquisition simpler. Indeed, although the web constitutes an invaluable resource, the abundance, richness, and often contradictory nature of the data available can easily be overwhelming. To acquire new information efficiently and successfully, one has to be able to search, filter, critically evaluate, and compare a virtually infinite list of results and sources, which are not all equally reliable, or reliable at all. This ability to effectively navigate the web, to read and interpret information coming from the media, and to evaluate and apply the knowledge gained from digital environments (often referred to as information literacy) has been described as the most important skill for the 21st-century learner (Eisenberg, 2003; Saunders et al., 2017). Information literacy is critical to transition from the information society we are living in, which is primarily concerned with collecting and disseminating data, to a knowledge society that transforms the available data and 
information into resources to empower people and improve the human condition (Alkali \& Amichai-Hamburger, 2004; Aviram \& Eshet-Alkalai, 2006; B. Jones \& Flannigan, 2006). In this study we investigated how adolescents search and filter the web for information about unsettled scientific dilemmas, addressing to what extent their capability to appraise web sources for accuracy, learn, and mold informed opinions is influenced by the control they exert over the online search experience, by the efficiency of their search strategies, and by the experience they have with searching the web for relevant factual information.

\section{State of the art}

As information literacy becomes increasingly relevant for nearly every academic and nonacademic endeavor, research has been conducted from a variety of disciplinary perspectives, from psychology, human-computer interaction and education, to marketing and design, often with diverging goals and distinct methodologies (Livingstone, 2004). Consequently, there is quite some blurriness and ambiguity in the literature, with different terms (e.g., computer literacy, digital literacy) often used interchangeably despite their overlapping but still fairly distinct definitions (Bawden, 2008; Porat et al., 2018). Overall, prior work has mostly focused on assessing the efficiency and effectiveness of students' online search behavior, and on their ability to identify and target reliable sources of information.

\section{Efficiency in adolescents' online search strategies}

Previous research evaluating students' efficiency when browsing and filtering the web for information (see Covello and Lei, 2010, for a review) focused on different measurements, using questionnaires and self-reports (e.g., Gui and Argentin, 2011; Ng, 2012; Porat et al., 2018; see Hargittai, 2010, for a comparative study of self-reports' efficacy), search engines' transaction logs (e.g., Toms and Latter, 2007; Walhout et al., 2015), verbal protocols (e.g., Greene et al., 2018; Greene et al., 2014; Kammerer and Gerjets, 2014), and video analyses of search patterns in tailored (e.g., modified results' page: Gwizdka and Bilal, 2017) or 
realistic (e.g., Google: Bilal and Gwizdka, 2018; Rennis et al., 2015) search engines. Notwithstanding these differences, this work converges to suggest that adolescents often do not implement optimal search strategies when navigating the web. For instance, they frequently utilize search engines rather than going straight to websites, often trusting the engines' query suggestions blindly (Gossen et al., 2011). Although this approach might circumvent their lack of relevant knowledge and general difficulty in formulating correct queries on their own, following the algorithm's predictions may lead to results that are popular and trending but not necessarily the most relevant or accurate. This risk becomes even more significant given the evidence suggesting that teenagers heavily rely on the search engines' rankings, tending to select the very first results obtained and rarely looking beyond the first page of results (Gwizdka \& Bilal, 2017; Kammerer \& Gerjets, 2014). When compared to adults, 10- to 16-year-olds are more likely to click on higher ranked results, spend less time on each web address (i.e., URL), but nevertheless take longer to reach a solution to the task at hand (Duarte Torres \& Weber, 2011), which is likely because of a stronger tendency to repeat the same queries and revisit the same result pages and websites (i.e., loopy browsing, Gossen et al., 2014). Moreover, when formulating queries to be used on search engines, they seem to prefer natural language to keywords (Bilal \& Gwizdka, 2018; Duarte Torres \& Weber, 2011), which would lead to more targeted and refined results.

\section{Efficiency in identifying appropriate sources of information}

From a strictly developmental and cognitive standpoint, adolescents should be generally pretty good at telling good from bad sources of information, as children as young as 4 years can already successfully identify which informant to trust and rely on (see Mills, 2013; Sobel and Kushnir, 2013, for reviews). However, several studies suggested that they often do not take into account or are not able to evaluate the reliability and credibility of the sources of the information they are presented with online (Hautala et al., 2018). For 
instance, Maitz et al. (2020) found that more than $90 \%$ of the web pages visited by 14-year-olds during a health search task (i.e., suggest whether to get rid of a hairy mole) were judged poor or unreliable by independent raters. In particular, adolescents seem to fail to consider those aspects of the websites that would be relevant to appraise their reliability, such as the presence of advertisements (Gossen et al., 2011; McGrew et al., 2018), and do not take into account the website's sponsors or political and industry affiliations (McGrew et al., 2018). Instead, they often focus on more superficial cues, such as the vaunted expertise of the person providing information (e.g., the source of health-related information claiming to be a doctor, Maitz et al., 2020), or the website appearance (Freeman et al., 2018). In this respect, a meta-analysis by Dresang (2005) indicated that young people tend to discard the information coming from text-only websites, preferring more interactive pages, rich with video and visual content. This tendency might make them especially susceptible to false or biased information (Britt \& Aglinskas, 2002). For example, McGrew et al. (2018) found that $52 \%$ of high-school students wrongfully believed that a grainy video claiming to document ballot stuffing in the 2016 Democratic primaries constituted strong evidence of voter fraud, although the video was actually shot in Russia.

\section{The impact of information literacy on learning outcomes}

Previous literature rarely offers insights on the impact of information literacy on learning outcomes that transcend the boundaries of academic achievements on higher education's specific subjects (e.g., Christ, 2004; Johnston and Webber, 2003; Storksdieck, 2016), with some exceptions. For instance, using verbal protocol analysis, Greene et al. (2018) found that the extent to which university students checked the consistency between different claims found on the web was positively related to their knowledge and comprehension of the topic at hand, although this relationship was not found to be statistically significant. Along these lines, undergraduate students were found to be better at justifying their

opinions about unsettled scientific topics (e.g., whether using mobile phones can be a 
health hazard: Mason et al., 2010) when they had reflected on the extent to which the consulted websites provided actual scientific evidence (see also Çoklar et al., 2017;

Kammerer et al., 2021; Zlatkin-Troitschanskaia et al., 2020 for similar work with university students). Moreover, Tu et al. (2008a) analyzed video captures of 14-year-olds' web searches about nuclear energy. In their task, participants were asked to search for answers to both "open-ended" (i.e., among all of the energy resources, what do you think is the best energy resource? Why?) and "close-ended" (i.e., What are the currently used energy resources in Taiwan?) questions. Coding of the video captures focused on several quality indicators such as number of keywords, visited pages, maximum depth of exploration, refinement of keywords, and number of words used in the first query. Their results indicate that some of these parameters (e.g., number of keywords used), along with participants' general web experience, predicted the accuracy of participants' answers, but only when they were searching answers to close-ended questions. Analyzing similar query patterns, Bilal (2000) found a positive correlation between the quality of the search strategies implemented by 12- to 13-year-old students and their success in solving fact-finding tasks (i.e., how long do alligators live in the wild vs. captivity?). In particular, they found that successful children had navigated and examined a higher percentage of hyperlinks and homepages, and looped searches and hyperlinks less frequently than unsuccessful children. However, more recently, Walhout et al. (2017) measured 14-year-olds' perceptual search processes using a combination of log files, eye-tracking data, surveys, and think-aloud protocols when they were asked to complete three tasks of differing complexity (i.e., fact-finding, cause-effect, and a controversial topic task). Their results showed that an increase in task complexity resulted in poorer task performance but in increased interaction with the search engine. In particular, when completing the controversial task (i.e., Does radiation from mobile phones have consequences?), participants made more search queries and used more keywords, longer formulation time, and considered a greater amount of search results (but still higher ranked in the results' page). 


\section{Assessing and boosting students' information literacy in educational settings}

Results from the comparative International Computer and Information Literacy Study (Fraillon et al., 2020), conducted in 2013 and 2018 among teachers and students from 2,200 schools across 14 countries, suggest that although in this time frame schools had been increasingly equipped with digital tools such as computers and tablets, this was often not accompanied by the actual implementation of such tools in the educational curricula. For example, ILCIS 2018 consisted of a battery of tasks developed to measure students' ability to use computers to collect, manage, produce, and exchange information (computer information literacy). Participants' scores indicated that in most Western countries (e.g., Germany, Finland, and the United States), the majority of students were at Level 2 of 4, indicating they "needed support." Italian students reached an average score of 461 (of 746), corresponding to the "basic skills" Level 1. Furthermore, only $18 \%$ of the Italian students reported regularly using computers during their classes on information technology, programming, and computer science, which is a lower percentage compared to students from other European countries such as Denmark (75\%) and Portugal (67\%; Fraillon et al., 2020). These findings are in line with other survey studies showing that only $5 \%$ of the students credit school for teaching them how to search and process online information (Strom et al., 2009).

In light of the research reviewed above, it seems evident that there is a considerable gap between the ever-rising awareness of the need to provide students with the opportunity to become information literate and the poor implementation of this process in school curricula. Indeed, although a variety of tools and interventions - games, tutorials, guidelines, workshops - have been developed over the last few years, their actual efficacy and potential is unclear and hard to assess, as they often stem from different perspectives and focus on diverse methods, outcomes, and goals (see Munn and Small, 2017, for a review). The efficacy of some of these interventions has been proven in higher education settings by introducing information literacy training within school curricula to boost 
students' ability to search scientific literature from specific databases, generally showing quite good and long-term success (e.g., Hegarty and Carbery, 2010; Kavšek et al., 2016; Wallace et al., 2000; Wegener, 2018). However, the evidence of successful interventions targeting younger students is generally scarce, if not absent. In this respect, the Joint Research Center of the European Commission published a support guide for stakeholders (DigComp; Kluzer and Priego, 2018), including case studies and interventions developed within the European Union with the aim of enabling people to acquire the digital skills they need to be successful in the workplace, at school, or simply as citizens. In the educational domain, most case studies suggested that interventions and tools were mostly successful when focusing on making students aware of their digital competences rather than boosting them (e.g., see the Task Project's tool).

\section{Factors influencing computer and information literacy}

Studies have addressed the impact of different personal, social, and motivational factors underlying individual differences in information literacy skills (see also Lewandowski and Kammerer, 2020 for a review of factors influencing viewing behaviour on search engine results pages). Evidence from the comparative ILCIS study (Fraillon et al., 2020) suggests that factors such as parental education, socioeconomic background, and students' expectations of attaining a university education were significant predictors of computer and information literacy across countries. A similar trend was found for participants' gender, with female participants scoring on average 11 points higher than male participants. Gender differences were also found in adolescents' online search efficiency, but generally pointing in the opposite direction, suggesting that boys may be more efficient searchers than girls (e.g., Large et al., 2002). For instance, Roy and Chi (2003) found that 13-year-old boys filtered information at an early stage in the search process, using a predominantly horizontal search pattern, which consists of opening multiple tabs simultaneously to check the veracity of different sources of information. Same-aged girls, 
on the other hand, were found to implement more vertical, linear search moves and to be generally more thorough than boys. The kind of task presented also has an impact on learning efficiency (e.g., Walhout et al., 2017). For instance, Bilal (2002) found that 12- to 13-year-olds solved fact-finding tasks with greater ease compared to more research-oriented assignments, where participants were asked to learn and report about more complex topics, such as the depletion of the ozone layer (Bilal, 2002).

Not too surprisingly, general experience and time spent in navigating web environments also has been found to have a solid impact on adults' navigational style (e.g., Palmquist and Kim, 2000; Thatcher, 2008) and on children's performance on tasks related to computer and information literacy (e.g., Bilal, 2000; Tu et al., 2008b). Even the frequency of use of information and communications technology applications in the classroom, along with the perception of having learned about computer and information technologies, was found to predict children's information literacy (Fraillon et al., 2020). Perceived self-efficacy (Hatlevik et al., 2018), self-regulated inquiries (Lai et al., 2018), as well as epistemological beliefs and previous knowledge about the topics one searches about (e.g., Corredor, 2006; Tu et al., 2008b), also seems to affect students' efficiency in searching, retrieving, and interpreting information from the web.

\section{The current study}

Contributing to the rapidly growing literature reviewed above, the present study explored how 14- to 17-year-olds navigate the web when they were tasked with making an informed suggestion about controversial topics (i.e., whether using deodorants containing aluminum compounds or drinking mineral water containing nitrates increase the risk of developing cancer). In addition to evaluating participants' overall search patterns, the factual knowledge they acquired, the accuracy of their suggestions, the completeness and clarity of their explanations, and interactions between these outcomes, we were interested in exploring the factors driving individual differences in search efficiency and learning 
outcomes. In particular, we have addressed the novel hypothesis that having control over the online search experience, along with having experience with searching the web specifically to obtain relevant factual information, may influence the overall quality of adolescents' online search efficiency and learning. We detail each hypothesis below.

\section{Volitional control over the search process}

As mentioned above, efficiently controlling the online search process is quite complex and demanding to: One has to know what to type in the search box, filter a pseudo-infinite list of results, evaluate the sources providing the information and the accuracy of the information provided, and finally decide when enough information has been collected and stop querying. Previous work suggests that the online search process taps into several cognitive skills, such as reasoning, working memory, attention, and perceptual speed (Sharit et al., 2008), as well as vocabulary and cognitive flexibility (Dommes et al., 2011). However, the media landscape also offers a constant stream of information that one does not control-TV news, YouTube channels, video bloggers, and social media feeds collecting and assembling information for consumption, presenting well-packaged stories that one can only absorb, endure, and later try to process, filter, and make sense of. Even though this process might be less costly from a cognitive perspective (Brossard, 2013) compared to situations in which one has to search actively, it may be even more demanding and taxing to evaluate and integrate information one has not put together oneself.

Indeed, active, self-directed learning has proven to be beneficial in educational settings across a variety of domains and subjects, contributing to the widespread idea that giving students some degree of control over the learning experience supports and boosts learning. In particular, recent experimental work indicates that even minimal forms of volitional control, such as allowing the learner to control the pace and order of the materials to be studied, enhance memory retention in both adults (e.g., Liu et al., 2007; D. Markant et al., 2014; Plancher et al., 2013; Voss et al., 2011) and children (e.g., Fantasia et al., 2020; 
D. Markant et al., 2016; Partridge et al., 2015; Ruggeri et al., 2019) compared to situations in which the learner is merely exposed (i.e., yoked) to other participants' study choices. By matching the content experienced during study across conditions, yoked designs isolate the effects of active control on learning. These benefits were proven to persist a week after the initial study session and were robust across different types of tasks and populations (D. Markant et al., 2016). Self-directed information sampling has been also linked to learning advantages in causal reasoning, where adult participants were asked to intervene - actively or by replicating actions made by someone else - on an unknown system to figure out which sensors turned on which lights (e.g., Sobel and Kushnir, 2006; Steyvers et al., 2003). In their review, Gureckis and Markant (2012) argued that besides the different valences of attention and motivation, just the act of making decisions about the timing, spacing, and order of information that active learners experience can enhance deeper processing. Additionally, because self-directed learners may gather data to specifically test a hypothesis they have in mind, in line with their existing knowledge, their mental state may simply not be matched to the yoked partners' search strategy. In this sense, the advantage of self-directed sampling would emerge only in cases where learners have a proper representation of the information space and are able to successfully monitor their own knowledge gap and uncertainty, sparing them the effort to allocate cognitive resources to redundant information (D. Markant \& Gureckis, 2014). Indeed, self-directed sampling does not always lead to more efficient and successful learning, particularly on very complex tasks (Schwartz, 1966). For example, Enkvist et al. (2006) found that participants who actively experimented on a multiple-cue inference task to predict the binary criterion on which a bug would be considered deadly produced poorer judgments about the criterion values. Along these lines, self-directed sampling can also result in bias-driven strategies in which learners tend to confirm their initial (and potentially wrong) hypothesis (e.g., Denrell, 2005) and perceive illusory correlations (e.g., Fiedler, 2000), which may result in overconfidence about the efficacy of their sampling capabilities (e.g., Juslin et al., 2007). 
Thus, this study expands previous work by exploring whether having volitional control over the online search experience impacts the accuracy and quality of the search process and of the knowledge acquired. For this purpose, we manipulated within participants whether they were free to search and navigate the web to collect the information they needed to form an opinion and make a suggestion (active condition) or could merely observe and follow another participant's search process (yoked condition).

\section{Experience in searching relevant information}

Evidence from Lenhart et al. (2007) indicates that the majority of 13- to 17-year-old adolescents use the web most often to visit social media platforms (71\%), to check websites about movies, TV shows, music groups, or sports stars (81\%), but also to look up news and current events $(77 \%)$. Some studies suggested that older teens (15- to 18-year-olds) also use the web to look up health-related information (66\%), particularly about sensitive topics that can cause embarrassment when discussed with other people (e.g., sex or mental health; Robards et al., 2017; Skinner et al., 2003; or see Freeman et al., 2018, for a comprehensive review). However, it is unclear whether and how different kinds of web experience and habits relate to adolescents' search efficiency and learning success. Previous studies suggested that the general experience of using computers (e.g., 5 days a week) was positively associated with students' information literacy (Fraillon et al., 2020). Yet, it seems improbable that using computers to play video games, to chat with friends, or to watch movies would make one a more efficient and conscious web user.

In this study, we contribute to the existing literature by investigating whether the frequency with which adolescents specifically search for factual information on the web (e.g., related to subjects covered in school, current events, or news stories), compared to other kinds of web experience, has a positive impact on their ability to search, filter, and consciously learn from the web. 


\section{Methods}

\section{Participants}

Forty-eight 14 - to 17 -year-old high-school students (13 female; $M_{\text {age }}=15.2$ years, $S D=$ 1.03) recruited from a secondary school in Livorno, Italy, voluntarily participated in the study. Institutional Review Board approval was obtained from the Ethics Committee of the Max Planck Institute for Human Development in Berlin (protocol: "WISE"), and parents gave informed consent for their children to participate before testing took place. Two additional participants were excluded from the analyses because of a certified intellectual disability or missing data.

\section{Design and procedure}

Students were tested in groups of 10 to 14 in the computer room at their school and were presented with an online survey consisting of two identically structured blocks, in a $2 \times 2$ within-subject design.

\section{Active and yoked research phase}

Each block presented a brief text describing a dilemma scenario in which a fictitious character expressed uncertainty about whether to use products containing one of two substances that have recently received controversial media coverage because of their potential carcinogenic effect: aluminum (A) in deodorants and nitrates $(\mathrm{N})$ in water. The text concluded with the fictitious character explicitly asking participants whether the use of products containing those substances was safe and whether there was actual scientific evidence supporting their connection to cancer (see Section A in the Appendix for the complete procedure).

The text included four "target" keywords (i.e., cancer, scientific evidence, aluminum/nitrates, deodorants/water), not made explicit as such to participants, which if searched on Google would have led to the most reliable (target) website being shown as a 
snippet (i.e., a box on top of the results page containing a summary of the main content of a website relevant to the user's search). ${ }^{\dagger}$ The target website belonged to a national association for cancer research (a nongovernmental organization [NGO]) and presented transparent and clear information about the connection of both substances to cancer..$^{\ddagger}$ Crucially, both pages on the target website contained all the information needed to make an informed suggestion in reply to the character's question, and to answer knowledge assessment questions correctly. Also, the two pages were comparable in terms of reading time (5 min).

Participants were asked whether they had previous knowledge about the presented topic (i.e., "Do you know anything about nitrates in water/Do you know anything about aluminum in deodorants?") and were then asked to search the web for 10 min (active block) or watch a 10-min video of another participant searching the web (yoked block) to make the informed suggestion. All participants completed the active block before the yoked block, but the two topics (A and N) were pseudorandomly assigned to the blocks, so that half participants started with Topic $\mathrm{A}$ in the active block and proceeded to Topic $\mathrm{N}$ in the yoked block, whereas the other half started with Topic $\mathrm{N}$ in the active block and proceeded to Topic A in the yoked block. Before entering the research phase, participants were explicitly informed about the subsequent tasks and were prompted to be as exhaustive and accurate as possible.

\section{Suggestion and justification}

After the 10-min active or yoked research phase, participants were asked to come up with a suggestion (i.e., to avoid/not avoid deodorants containing aluminum; to avoid/not avoid drinking water containing nitrates) as well as a justification for this suggestion (maximum

\footnotetext{
$\dagger$ Note that omitting the keyword "scientific evidence" would have still resulted in the "target" website being listed first, but not as a snippet.

$¥$ Link Alumnium; Link Nitrates
} 
of 150 words).

\section{Source reliability}

For each block, participants then had to provide a link to the most reliable and the least reliable source encountered while researching and were asked to select the reason for their choice from an eight-item multiple-choice list (see Table A1).

\section{Factual knowledge}

For each block, participants were then presented with three multiple-choice questions assessing the knowledge gained in the researched topic (see Table A3).

\section{Information search habits}

After having completed the active block, participants were asked to report the frequency with which they usually search for information online, which search engines they preferred, and how often search engines were utilized for various purposes, on a Likert scale ranging from 0 (never) to 10 (every day).

\section{Results}

As we found no effect of topic (A or N) on any of the outcomes considered in the study, we excluded this variable for the following analysis (please note that the full data set is available on the OSF platform at this link). In this section, we first report the overall descriptive statistics of the measures considered (previous knowledge, accuracy of the suggestion and quality of the justification provided, sources selected as most/least reliable), merged across conditions, and interaction effects found between these outcomes. Second, we give an overview of participants' web habits. Third, we present the analyses of participants' search patterns in the active blocks. Finally, we present the analyses of the factors we hypothesized might contribute to participants' performance. In particular, we examined whether being given control over the search process (i.e., active vs. yoked 
condition), previous knowledge, and web habits as well as efficiency in navigating the web elicited in the active condition had an impact on the learning outcomes considered. Additionally, we explored whether previous knowledge and web information search habits also had an impact on participants' search efficiency.

\section{Overall measures}

\section{Previous knowledge: Had participants heard about these topics before?}

Overall, $12.5 \%$ of the students indicated that they had heard about one of the presented topics before (Topic A: $n=6 / 48$; Topic N: $n=6 / 48$ ), whereas only two of 48 students had heard about both topics, and 70.8\% $(n=34 / 48)$ had heard about neither.

\section{Suggestion and justification}

The Italian Association for Cancer Research (AIRC) has reassured the public that it is safe to use both of these products, as there is no evidence supporting the alleged risks. In particular, epidemiological studies have not shown significant relationships between deodorant use and the occurrence of any cancer, and specific studies on aluminum have not found any relationship between its effect on estrogen receptors and breast cancer. However, studies on nitrates have shown that, when ingested, about $20 \%$ of these compounds can be transformed into nitrosamines, which can be considered carcinogenic if introduced directly and at high doses. Therefore, according to the World Health Organization and the Italian law, nitrates in tap and bottled water must not exceed $50 \mathrm{mg} / \mathrm{L}$.

In total, $58.3 \%$ of participants $(n=28)$ gave positive suggestions concerning both products; that is, they thought that the characters could safely continue using deodorants containing aluminum and continue drinking water containing nitrates, whereas $10.4 \%$ had the opposite opinion, that is, that the characters should stop using both products $(n=$ 5/48). Thirty-one percent of the participants gave a positive suggestion to the fictitious character concerning at least one of the allegedly carcinogenic products (Topic A: $n=$ 
7/48; Topic N: $n=8 / 48)$.

Participants were also asked to justify the given suggestions with a short text. Three chemistry experts blind to the research questions rated the accuracy and completeness of the justifications on a scale of 0 (lowest possible score) to 10 (highest possible score). We assessed raters' agreement by computing the intraclass correlation coefficient (ICC) with a one-way random effect model and average unit: $\mathrm{ICC}=.881 ; 95 \%$ confidence interval $(\mathrm{CI})$ $[.83, .91] ; F(86,174)=8.39 ; p<.001$. As the raters' agreement was very good, an average score was calculated for each participant. On average, the justification score obtained by participants was $-=4.59(\operatorname{Min}=1, \operatorname{Max}=9, S D=2.38)$.

\section{Source reliability}

The links participants provided as most/least reliable sources of information were coded into different categories: NGO websites, official international governmental organization (IGO) websites, commercial websites, personal blogs, and Wikipedia pages (see Table A2). As illustrated in Figure 1a, $68.8 \%$ of participants deemed NGO websites as the most reliable (94.5\% of the NGO links provided were the target website). Overall, $72.9 \%$ of the websites participants indicated as most reliable provided at least two of the three pieces of information required to correctly answer the knowledge assessment questions. Interestingly, we found no systematic trend in attributing unreliability to any of the source types (see Figure 1b). Sixty-nine percent of participants perceived sources as reliable because they were clear and provided scientific evidence $(52 \%)$, but no reason stood out when indicating why the provided sources were the least reliable.

\section{Knowledge assessment}

Participants' answers to the three multiple-choice questions were coded as " 1 " when they were correct and "0" otherwise. On average, participants answered correctly about half of the questions $(M=.45, S D=.29)$. 

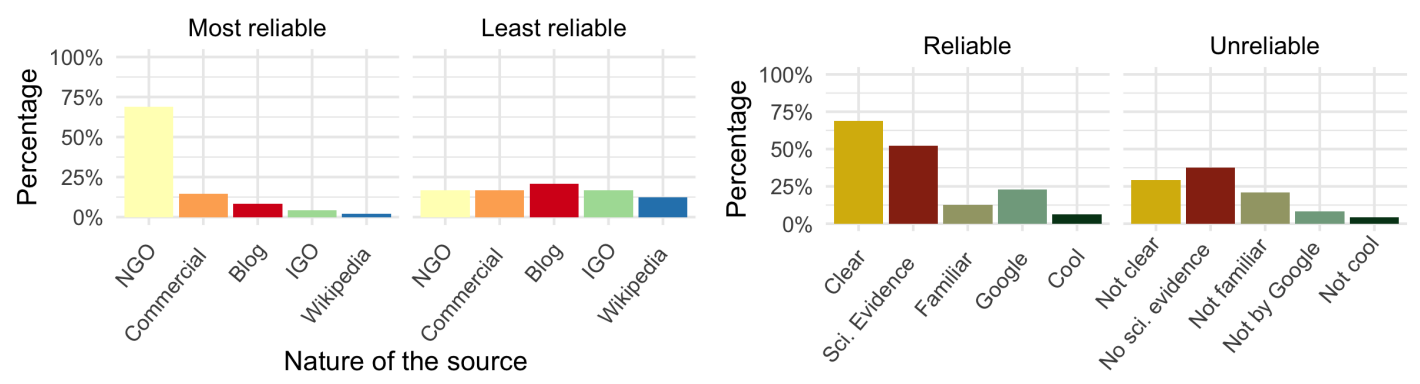

(a) Which source was the most or least

(b) Why was the source the most or least reliable? reliable?

\section{Figure 1}

Percentage of the websites indicated by participants as most and least reliable, coded by source type (Panel a) and the reasons why participants had selected those links as most or least reliable (Panel b). IGO= International governmental organization; $N G O=$ nongovernmental organization; sci = scientific.

\section{Interactions between learning outcomes}

We ran several mixed-effects regression models to examine potential interactions between the above-mentioned measures and the two conditions. ${ }^{\S}$ We found that neither the proportion of correct answers participants gave in the factual knowledge assessment ( $p=$ $.27)$, nor the suggestions given $(p=.52)$ predicted the justifications' scores. Additionally, we ran three models predicting each learning outcome by the probability of providing a fully informative link, that is, a link that contained at least two of the three pieces of information needed to answer the knowledge assessment questions correctly. These models

\footnotetext{
$\S$ All generalized linear mixed models were run using the $l m e 4$ package, version v1.1-23, inserting a random intercept for subjects. Effect sizes and $95 \%$ confidence intervals (CIs) for significant effects of logistic regressions are reported in terms of relative odds ratios (OR), which indicate the multiplicative change in the odds of providing a positive suggestion (binomial) or a fully informative link (binomial), which is associated with a unit change in the given predictor.
} 
revealed that participants who provided such links were slightly more likely to answer more questions correctly $(\mathrm{OR}=0.65,95 \% \mathrm{CI}[0.23,1.78], p=.05)$ but not to give different suggestions $(p=.47)$ or to get higher justification scores $(p=.28)$.

\section{Online information search habits}

As can be seen in Table 1, adolescents reported they most often searched the web for entertainment content (e.g., video and games). Indeed, this was ranked as the most frequent activity by $37.5 \%$ of participants. In total, the percentage of participants who ranked factual information search (i.e., searching for interesting facts, school-related content, or daily news) as the most pursued online research activity amounted to $43.8 \%$.

\section{Table 1}

Mean frequency $(0=$ never; $10=$ on a daily basis) of participants' information search activities on the web and percentage of participants who ranked each search activity as the most pursued on the web

\begin{tabular}{lccc} 
Activity & Mean & $\boldsymbol{S D}$ & Ranked 1st by \\
\hline Entertainment & 8.54 & 2.23 & $37.5 \%$ \\
Interesting facts & 7.85 & 1.84 & $33.3 \%$ \\
School-related content & 6.56 & 2.34 & $8.3 \%$ \\
Products to purchase & 6.52 & 3.26 & $12.5 \%$ \\
Daily news & 4.31 & 3.03 & $2.2 \%$ \\
News about celebrities & 4.58 & 3.33 & $6.2 \%$
\end{tabular}

\section{Information search patterns in the active blocks}

Video captures of participants' search during the active blocks were coded by a blind and independent observer using the Datavyu video-coding software (Datavyu-Team, 2014). Five video captures were missing because of technical problems, leaving $n=43$ 
participants for the following analyses. The coding focused on two main aspects: the characteristics of the websites consulted and those of the inquiry process. As in the previous analysis of source reliability, the websites participants consulted were coded by type. For each participant, we calculated the percentage of pages consulted and the average time spent on pages by source type. Results are reported in Table 2 .

In Table 3 we report the coding results concerning all the characteristics of the inquiry process that have been previously identified as indicators of web search efficiency (e.g., Tu et al., 2008b). As participants were explicitly instructed to use the Google search engine, we did not include "search engine" among the indicators. Also, note that none of the participants used hyperlinks or typed in a specific link directly.

Overall, only $39.54 \%$ (17 of 43) of participants used a keyword-based query, that is, did not use any unnecessary conjunctions or specifications as one would do using natural language. Among them, $5.90 \%$ used none of the four target keywords, $11.76 \%$ used just one, $58.82 \%$ used two, and $23.52 \%$ used three. Interestingly, none of the participants used the cue "scientific evidence," although this was explicitly mentioned in the text as the main goal of the research task.

\section{Factors contributing to participants' performance}

\section{Active versus yoked: Does volitional control over the search process impact learning outcomes?}

We fitted three generalized mixed-effects models predicting each learning outcome (i.e., knowledge assessment, justification score, suggestion, and provision of a fully informative link) with fixed effects of condition (i.e., active and yoked), and their interactions. The models show that participants in the yoked condition were less likely to answer the knowledge questions correctly $(\beta=-0.38,95 \%$ CI $[-0.75,-0.01], p=.04)$ but more likely to get higher justification ratings $(\beta=0.42,95 \%$ CI $[0.00,0.83], p=.05)$. Learning condition did not have an effect on the suggestions they gave to the fictitious character $(p=.44)$, or 


\section{Table 2}

Summary of the sources consulted during the active research blocks: Proportion of participants who visited each source type at least once, average percentage of page visits of the total of all pages consulted by source type, and average time spent on each source type across all queries

\begin{tabular}{lcccc} 
& Visited at least once & \multicolumn{2}{c}{ Total pages visited } & \multicolumn{2}{c}{ Time spent on page (s) } \\
\hline Source type & Percentage (participants) & Percentage (source type) & Mean & SD \\
\hline NGO & $93.02 \%$ & $52.2 \%$ & 273.12 & 162.99 \\
Commercial & $65.12 \%$ & $29.8 \%$ & 85.6 & 126.85 \\
Blog & $18.60 \%$ & $4.4 \%$ & 11.21 & 34.75 \\
IGO & $16.28 \%$ & $3.4 \%$ & 16.72 & 57.63 \\
Magazine & $16.28 \%$ & $6.4 \%$ & 6.42 & 20.39 \\
Wikipedia & $11.63 \%$ & $2.6 \%$ & 11.81 & 36.53 \\
Scientific journal & $2.33 \%$ & $1.2 \%$ & 2.28 & 14.94
\end{tabular}

Note. $\mathrm{NGO}=$ nongovernmental organization; $\mathrm{IGO}=$ international governmental organization.

on the likelihood of providing a fully informative link $(p=.08)$.

As illustrated in Figure 2, a paired Wilcoxon signed-rank test confirmed that the average of correct answers was significantly higher for the active blocks $(Z=-8.48, p<.001$, $r=1.22$ ). Yet participants received on average higher ratings for their justifications in the yoked condition $(Z=-7.74, p<.001, r=1.11)$.

\section{Does previous knowledge predict learning outcomes and search efficiency?}

Not too surprisingly, previous knowledge about the topics to be researched significantly predicted learning outcomes. Mixed-effects regression models predicting each of the learning outcomes separately by participants' previous knowledge (factor: Yes/No) and their interactions with learning condition revealed that participants who stated at the beginning of the test that they had heard about the topic(s) before were more likely to answer the multiple-choice questions correctly $(\beta=0.98,95 \%$ CI $[0.29,1.67], p<.01)$ and 


\section{Table 3}

Summary of the characteristics of the inquiry process: The average of each of the actions listed has been calculated across queries, unless indicated otherwise. Time excludes time spent taking notes

\begin{tabular}{lcc} 
Inquiry characteristic & Average & $\boldsymbol{S D}$ \\
\hline Queries & 2.18 & 1.36 \\
Keywords & 0.53 & 0.80 \\
Keywords/query & 2.49 & 0.76 \\
Natural language & 1.65 & 1.11 \\
Reformulations & 0.16 & 0.43 \\
Pages consulted & 3.25 & 2.18 \\
Pages/query & 1.86 & 1.28 \\
Position rank & 3.36 & 1.72 \\
Lowest position rank (of 10) & 4.67 & 3.67 \\
Time (s) & 407.16 & 145.23 \\
Time/page (s) & 185.05 & 146.40
\end{tabular}

to get higher justification ratings $(\beta=0.77,95 \% \mathrm{CI}[0.06,1.47], p=.03)$. Interestingly though, knowing about the topics had a negative interaction effect in the yoked condition, indicating that when participants did not exert control over the search process, they were less likely to answer the knowledge questions correctly even if they knew something about the subject before actually gaining the (new) information $(\beta=-0.98,95 \%$ CI $[-2.00,0.04]$, $p=.05)$. On the other hand, previous knowledge did not affect participants' suggestions to the fictitious character in any learning condition $(p=.08)$, nor the likelihood of consulting a fully informative link $(p=.09)$, nor any characteristic of the inquiry process $(p \mathrm{~s}>.11)$. 


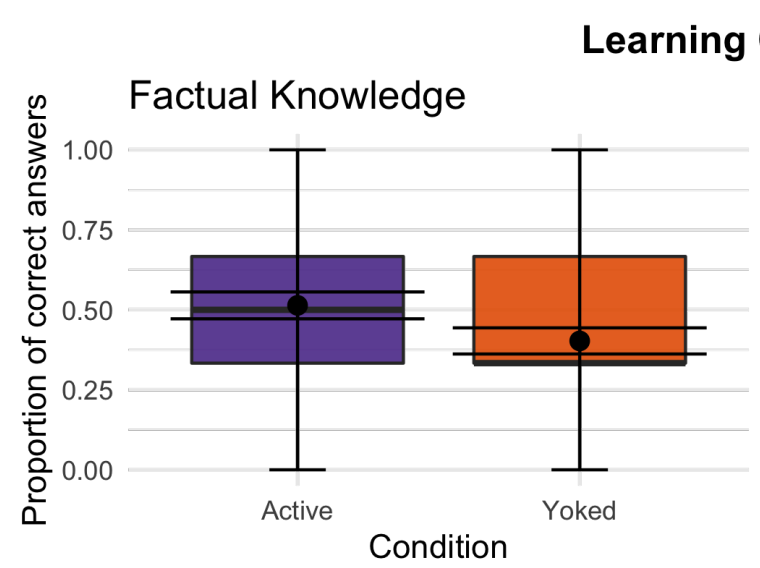

Fully Informative Link

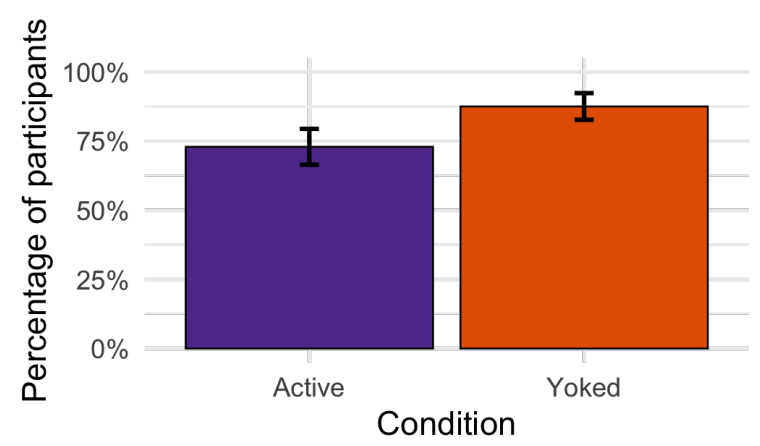

Outcomes

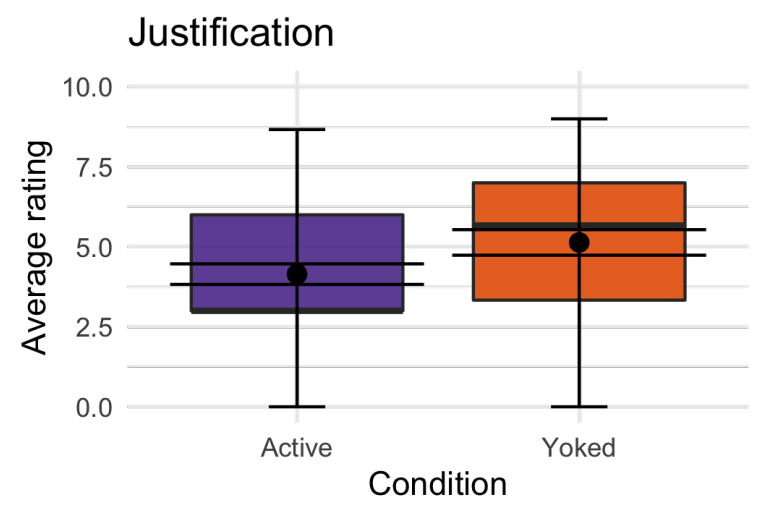

Suggestion

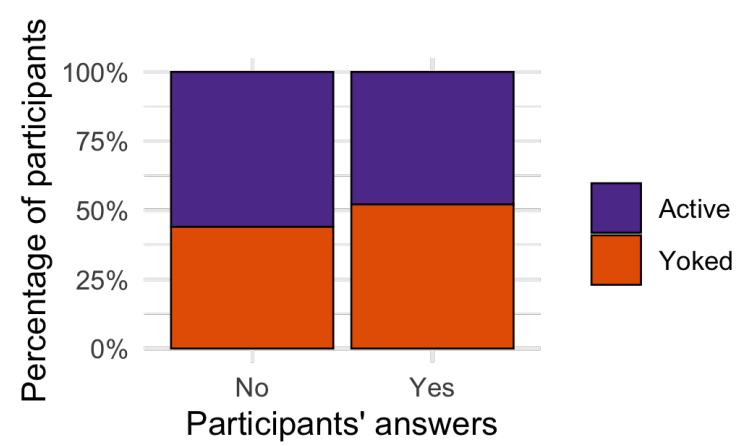

Figure 2

Outcome measures used in the study: Knowledge assessment, justification rating, provision of a fully informative link, and suggestion. Bars represent $95 \%$ bootstrapped confidence intervals.

\section{Do web information search habits predict learning outcomes and search efficiency?}

We ran three regression models, predicting each of the learning outcomes by the overall frequency of online information search, by the habit of searching the web for factual information (factor: Yes/No), and by search activity. The first model showed that the overall frequency did not predict any of the learning outcomes considered ( $p \mathrm{~s}>.12)$; the second model showed a nonsignificant effect $(p=.59)$. However, by looking at each activity separately, the third model revealed that participants who more frequently searched the 
web to perform school-related assignments were more likely to achieve higher justification ratings $(\beta=0.49,95 \%$ CI $[0.17,0.82], p<.01)$. No further predictors were found to be significant in this case; nor were these predictive of any other learning outcome. Finally, we ran several models predicting different characteristics of the inquiry process by participants' information search habits, which revealed no significant results ( $p$ s $>.14$ ).

\section{Does online search efficiency impact learning outcomes?}

We fit several linear mixed-effects models, predicting each learning outcome by the characteristics of the inquiry process and of the websites consulted. The models revealed that participants who visited IGO websites were more likely to answer more questions correctly $(\beta=0.42,95 \%$ CI $[-0.01,0.84], p=.05)$. The number of reformulations negatively predicted the quality of the justification provided $(\mathrm{OR}=-0.31,95 \%$ CI $[-0.62$, -0.01], $p=.04)$. In contrast, participants who spent more time reading blogs $(\beta=0.36$, $95 \%$ CI $[0.06,0.67], p=.01)$ and NGO websites $(\beta=0.43,95 \%$ CI $[0.02,0.84], p=.03)$ were more likely to obtain higher justification ratings. Moreover, participants who visited NGO websites were more likely to suggest the fictitious character continue using the products $(\mathrm{OR}=0.27,95 \%$ CI $[0.02,1.15], p=.04)$. Somewhat surprisingly, no other aspects of the inquiry process significantly predicted learning outcomes.

\section{Discussion}

In this project we examined how adolescents search and filter information on the web when they are tasked with making and justifying an informed suggestion about unsettled scientific issues. Beyond assessing the effect of factors that have already been identified as potential influences on adolescents' information literacy (i.e., previous knowledge and search efficiency), we were particularly interested in exploring the possibility that having control over the online search experience, along with having experience with searching the web to obtain factual information, would positively contribute to the quality and informativeness with which opinions, such as whether using a certain product might be a 
health hazard, are formed. Generally, we found that participants' learning performance was rather poor, although a vast majority had indeed identified informative and accurate web sources and provided the right suggestion (i.e., it is indeed safe to use the controversial products).

To our knowledge, our study was the first to compare active and yoked information acquisition on the web, within participants, and in a naturalistic Google environment. Notably, our results indicate that having or lacking volitional control over the search process had a differential impact on the learning outcomes considered. In particular, our results suggest that having control over the information flow in the active blocks (i.e., being able to decide what to search, which keywords to use, which source to consult, and for how long) supported participants' retention of specific factual information, as measured by the knowledge assessment task. This is in line with the previous studies with adults and developmental work reviewed in the Introduction, robustly showing that even minimal forms of volitional control tend to result in memory improvements across a variety of tasks when compared to situations in which one lacks this possibility (Liu et al., 2007;

D. Markant et al., 2014; D. Markant et al., 2016; Murty et al., 2015; Partridge et al., 2015; Pezzulo et al., 2016; Ruggeri et al., 2019; Voss et al., 2011). However, our results also indicate that being a passive observer of the search process, in the yoked blocks, resulted in more accurate and elaborate justifications. This apparently contradictory finding can be potentially explained by taking into account the different nature of this task, compared to the knowledge assessment task. Indeed, similar trends have been found in spatial and spatial navigation tasks. For example, Plancher et al. (2013) compared active drivers and yoked passengers in a virtual driving experiment. Active participants were assigned to one of two conditions: an interaction condition, in which they drove a car along a route dictated by the experimenter, and a planning condition, in which they decided which direction to turn at each intersection and their choices were carried out by the experimenter. Compared to a yoked condition in which participants simply watched a 
video of the driving experience generated by active participants, both active conditions led to better memory for the layout of the virtual environment and the route taken. Moreover, performance in the planning condition was higher than in the interaction condition, suggesting that deciding how to explore enhanced memory independent of the physical act of exploring itself. This is in line with a number of studies showing that certain forms of spatial memory (e.g., memory for the distances between landmarks) are enhanced by active navigation of the environment (see Chrastil and Warren, 2012, for a review).

Interestingly, however, just like in our work, the same study found the opposite pattern in recognition memory for objects encountered along the route, with passive observers showing better recognition relative to both active conditions (see also Brooks, 1999). Similarly, some studies found that participants who were given volitional control when exploring immersive and complex virtual environments or 3D objects had equal (Foreman et al., 2004; Keehner et al., 2008; Wilson, 1999) or even worse route and survey knowledge (i.e., configural information to take novel shortcuts and detours between locations) than participants who were passively exposed to the same content (Attree et al., 1996; Marchak \& Zulager, 1992; Richardson et al., 1981). For instance, Wilson and Peruch, 2002 showed that young adults who explored a virtual environment through a prerecorded tour of similar experiences were significantly more accurate in their judgments of orientation and paths to the target object than active explorers. Generally, in a review of these findings, Chrastil and Warren, 2012 proposed that encoding certain aspects of the environment, such as full route and survey knowledge, requires mental manipulation of such properties but also the allocation of attention and encoding in working memory, which in turn may be constrained when participants are also actively involved in the decision-making process. In this sense, it is plausible that in the current study, saving participants the cognitive effort of deciding how to navigate the web allowed them to pay more attention and focus on the quality of the information provided, allowing them later to formulate more rigorous and conclusive arguments. Yet, why would they fail at the knowledge assessment task? On the 
one hand, it may be that while the yoked exposure promoted a broader view of the problem considered, enabling participants to allocate their attention in weighting counter-evidence and critically evaluate the information to which they were exposed, the effort of putting together such information somehow hindered the encoding of specific factual information. On the other hand, it is worth considering that this effect could also just be a result of always having participants complete the yoked block after the active block. In particular, this may have affected our results in two ways. First, completing the questionnaires following the active block might have unconsciously prompted participants to focus their attention on different aspects of the video they watched, for instance, on the reliability of the sources and the information. Second, although participants already knew about the justification task at the beginning of both research phases, they might have realized what was really required to succeed at this task only after having done it for the first time. Yet, it is unlikely that such awareness would have affected the knowledge assessment task, as it was practically impossible for participants to predict the specific facts the multiple-choice questions addressed. In support of this interpretation, previous work suggests that providing participants with specific instructions about what to pay attention to might mitigate the differences found within subjects' performance in active and yoked exploration of complex virtual environments (Taylor et al., 1999; Wilson \& Peruch, 2002).

Not too surprisingly, and in line with previous work, we found that already being familiar with the topic(s) to be researched helped and supported subsequent retention of factual knowledge, resulting in more accurate and evidence-based judgments (Hailikari et al., 2008; Hembrooke et al., 2005). Interestingly, our results suggest that this advantage was absent in the yoked condition. Thus, when participants did not exert control over the search process, they were less likely to answer the questions correctly even if they knew something about the subject before actually gaining novel information. As discussed by Gureckis and Markant (2012), it is likely that in this study context, participants' previous knowledge about the topics may not have been matched in the yoked partners' search, hindering their 
chance to directly test their intuitions and eventually confirm their hypotheses and resulting in a potentially frustrating experience.

Contrary to what has been found in previous work (Kelly \& Cool, 2002; White et al., 2009; Wildemuth, 2004), previous knowledge did not seem to impact the efficiency of participants' inquiry strategies (e.g., keywords used, reformulations, websites consulted, etc.). However, this inconsistency may also be attributable to the different definition of familiarity adopted in the studies mentioned above, where the benefit of having previous knowledge was assessed by comparing search effectiveness of users identified as experts and nonexperts within different domains (e.g., medical doctor vs. nonmedical doctor searching for health-related information).

Notably, our findings show that the majority of participants endorsed the reliability of nonprofit NGO websites, such as the National Association for Cancer Research, which in our case also represented the best source of information needed to succeed on the learning tasks. This finding is consistent with the many studies showing that adolescents deem NGO or IGO websites (i.e., the National Health Service in the United Kingdom: Gray et al., 2005, or the Mayo Clinic in the United States: Malbon et al., 2012) as the most reliable for health-related information (Gray et al., 2002; R. K. Jones \& Biddlecom, 2011a, 2011b). In this respect, more than the half of our participants indicated they attributed trust and reliability to web sources based on the quality of the information provided, such as its clarity (Selkie et al., 2011) and the degree to which it provided scientific evidence. However, even if to a lesser extent, participants also inferred reliability from other, less content-related aspects of the web source, such as its familiarity (i.e., whether they had heard of it before) and its position in Google's list of results (Gossen et al., 2014). Surprisingly, participants did not seem to agree on what kind of websites are least reliable, and they did not systematically distrust Wikipedia and similar sources, as found in previous studies (e.g., Henderson et al., 2013). This lack of expectations should be further investigated, especially in relation to adolescents' critical-thinking competence and more 
specifically to their ability to detect fake news.

Generally, the characteristics of the inquiry process observed in this study resembled the general trends found with adolescents in similar web-research-oriented tasks. For instance, participants in our study formulated queries using natural language rather than keywords, did not use hyperlinks (Bilal \& Gwizdka, 2018) and never went beyond the first page of Google results (Druin et al., 2009; Gossen et al., 2011; Walhout et al., 2017). They consulted predominantly the first three web pages in the list of results (Kammerer \& Gerjets, 2014) and spent a relatively short time (i.e., about $3 \mathrm{~min}$ ) on each page (Duarte Torres \& Weber, 2011). All participants used the Google search function rather than typing in a specific website (Gossen et al., 2011; Kobayashi et al., 2006). Crucially, however, our results suggest that only a few characteristics of the inquiry process were predictive of the quality of the learning outcomes. In particular, spending more time reading information provided by NGO websites resulted in greater - though not great - performance on the knowledge assessment task. Moreover, more frequent use of reformulations led participants to provide lower rated justification; in contrast, Tu et al. (2008b) showed that refinement of keywords predicted the accuracy of participants' answers. Yet this effect was found only when participants were tasked with searching for answers to close-ended questions, like in other studies reporting a relationship between the quality of students' learning and their information search strategies (e.g., Bilal, 2000; Greene et al., 2018; Greene et al., 2014). Taken together, these results suggest that understanding such effects on research-oriented tasks might necessitate more sophisticated classification of the inquiry's characteristics (e.g., Bilal and Gwizdka, 2018; Liu et al., 2010), which may better reflect the complexity and amplitude of tasks such as the one used in this study.

Importantly, we found that having the habit, that is, having more experience in searching the web to complete school assignments, helped students reflect on the information found on the web, resulting in higher rated justifications for their opinions. This is an 
encouraging result from the educational point of view, as it seems to suggest that training students to independently perform research tasks may indirectly support the development of critical reasoning, even about topics that are not directly relevant to their academic achievements. Future endeavors should address this possibility more directly, by evaluating the efficacy of such a simple, yet potentially effective training. For the same purpose, research should further systematically analyze other factors that may potentially contribute to adolescents' ability to search, filter, and learn from the web, addressing, for instance, the impact of cognitive factors (e.g., meta cognitive skills, working memory, attention) and academic achievement, generally focusing more on individual differences, for example, by implementing longitudinal designs.

\section{Conclusion}

To conclude, in this paper, we laid the groundwork for future research to investigate how active involvement in the search process may have a differential impact on learning outcomes, suggesting that the cognitive effort of having to search and filter the vast and infinite space of web information may support adolescents' ability to acquire knowledge, while being spared such effort may help them critically reflect on the quality of the information found, provided that the information sources to which they are exposed are reliable. This study also raises the uplifting possibility that training web-search abilities for school-related activities can support online learning outcomes beyond the boundaries of pure academic achievements.

In the digital era, where there is the ever-increasing power to shape political and social discourse with just one click, the ability to search, filter, evaluate, and integrate online information is becoming the necessary foundation for conscientious citizenship. Our findings highlight the crucial need to know more about the factors impacting adolescents' online search efficiency and success, with the goal of developing more effective tools to boost their critical thinking and societal participation. 


\section{Acknowledgments}

We would like to thank Leon Gellrich for coding participants' behavior during the active search and Ben Opitz for the insightful discussions about the educational implications of our findings. We also thank the Istituto Buontalenti-Cappellini-Orlando in Livorno, for providing us the opportunity to recruit and test students on site. Last but not least, we would like to express our gratitude to the teachers Eleonora Aquilini and Sandro Jurinovich for rating participants' justifications. 


\section{References}

Alkali, Y. E., \& Amichai-Hamburger, Y. (2004). Experiments in digital literacy.

CyberPsychology \& Behavior, 7(4), 421-429. https://doi.org/10.1089/cpb.2004.7.421

Attree, E., Brooks, B., Rose, F., Andrews, T., Leadbetter, A., \& Clifford, B. (1996).

Memory processes and virtual environments: I can't remember what was there, but i can remember how i got there. implications for people with disabilities. In $P$. Sharkey (Ed.), Proceedings of the 1st European Conference on Disability, Virtual Reality and Associated Technologies.Technologies (ECDVRAT 1996), 117-121.

Aviram, A., \& Eshet-Alkalai, Y. (2006). Towards a theory of digital literacy: Three scenarios for the next steps. European Journal of Open, Distance and E-Learning, $9(1)$.

Bawden, D. (2008). Origins and concepts of digital literacy. In C. Lankshear \& M. Knobel (Eds.), Digital literacies: Concepts, policies and practices (pp. 17-32). Peter Lang Publishing.

Bilal, D. (2000). Children's use of the yahooligans! web search engine: I. cognitive, physical, and affective behaviors on fact-based search tasks. Journal of the American Society for Information Science, 51(7), 646-665. https://doi.org/10.1002/(SICI)1097-4571(2000)51:7<646::AID-ASI7>3.0.CO;2-A

Bilal, D. (2002). Children's use of the yahooligans! web search engine. iii. cognitive and physical behaviors on fully self-generated search tasks. Journal of the American Society for information science and technology, 53(13), 1170-1183. https://doi.org/10.1002/asi.10145

Bilal, D., \& Gwizdka, J. (2018). Children's query types and reformulations in google search. Information Processing 83 Management, 54(6), 1022-1041. https://doi.org/10.1016/j.ipm.2018.06.008 
Bouzembrak, Y., Klüche, M., Gavai, A., \& Marvin, H. J. (2019). Internet of things in food safety: Literature review and a bibliometric analysis. Trends in Food Science 8 Technology, 94, 54-64. https://doi.org/10.1016/j.tifs.2019.11.002

Britt, M. A., \& Aglinskas, C. (2002). Improving students' ability to identify and use source information. Cognition and Instruction, 20(4), 485-522. https://doi.org/10.1207/S1532690XCI2004_2

Brooks, B. M. (1999). The specificity of memory enhancement during interaction with a virtual environment. Memory, 7(1), 65-78. https://doi.org/10.1080/741943713

Brossard, D. (2013). New media landscapes and the science information consumer. Proceedings of the National Academy of Sciences of the United States of America, 110 (Supplement 3), 14096-14101. https://doi.org/10.1073/pnas.1212744110

Chrastil, E. R., \& Warren, W. H. (2012). Active and passive contributions to spatial learning. Psychonomic Bulletin 8 Review, 19(1), 1-23. https://doi.org/10.3758/s13423-011-0182-x

Christ, W. G. (2004). Assessment, media literacy standards, and higher education. American Behavioral Scientist, 48(1), 92-96. https://doi.org/10.1177/0002764204267254

Çoklar, A. N., Yaman, N. D., \& Yurdakul, I. K. (2017). Information literacy and digital nativity as determinants of online information search strategies. Computers in human behavior, 70, 1-9. https://doi.org/10.1016/j.chb.2016.12.050

Corley, E. A., Kim, Y., \& Scheufele, D. A. (2011). Leading us nano-scientists' perceptions about media coverage and the public communication of scientific research findings. Journal of Nanoparticle Research, 13(12), 7041-7055. https://doi.org/10.1007/s11051-011-0617-3

Corredor, J. (2006). General and domain-specific influence of prior knowledge on setting of goals and content use in museum websites. Computers $\&$ Education, 47(2), 207-221. https://doi.org/10.1016/j.compedu.2004.10.010 
Covello, S., \& Lei, J. (2010). A review of digital literacy assessment instruments. IDE-712 Front-End Analysis Research. Analysis for Human Performance Technology Decisions., 1-31.

Datavyu-Team. (2014). Datavyu: A video coding tool. http://datavyu.org

Denrell, J. (2005). Why most people disapprove of me: Experience sampling in impression formation. Psychological Review, 112(4), 951. https://doi.org/10.1037/0033-295X.112.4.951

Dommes, A., Chevalier, A., \& Lia, S. (2011). The role of cognitive flexibility and vocabulary abilities of younger and older users in searching for information on the web. Applied Cognitive Psychology, 25(5), 717-726. https://doi.org/10.1002/acp.1743Citations:41

Dresang, E. T. (2005). Access: The information-seeking behavior of youth in the digital environment. Library Trends, 54(2), 178-196. http://hdl.handle.net/2142/3475

Druin, A., Foss, E., Hatley, L., Golub, E., Guha, M. L., Fails, J., \& Hutchinson, H. (2009). How children search the internet with keyword interfaces. Proceedings of the 8th International conference on interaction design and children, 89-96.

Duarte Torres, S., \& Weber, I. (2011). What and how children search on the web. Proceedings of the 20th ACM international conference on Information and knowledge management, 393-402. https://doi.org/10.1145/2063576.2063638

Eisenberg, M. The big6 approach to information and technology literacy. SSRN. 2003. https://doi.org/http://dx.doi.org/10.2139/ssrn.3424860.

Enkvist, T., Newell, B., Juslin, P., \& Olsson, H. (2006). On the role of causal intervention in multiple-cue judgment: Positive and negative effects on learning. Journal of Experimental Psychology: Learning, Memory, and Cognition, 32(1), 163-179. https://doi.org/10.1037/0278-7393.32.1.163

Eurostat. (2020). Being young in europe today - digital world (Technical report). European Union. Statistical Office of the European Communities, Luxembourg. 
https://ec.europa.eu/eurostat/statistics-

explained/index.php/Being_young_in_Europe_today___digital_world

Fantasia, V., Markant, D. B., Valeri, G., Perri, N., \& Ruggeri, A. (2020). Memory

enhancements from active control of learning in children with autism spectrum disorder. Autism, 24(8), 1995-2007. https://doi.org/10.1177/1362361320931244

Fiedler, K. (2000). Beware of samples! a cognitive-ecological sampling approach to judgment biases. Psychological Review, 107(4), 659-679.

https://doi.org/10.1037/0033-295X.107.4.659

Foreman, N., Sandamas, G., \& Newson, D. (2004). Distance underestimation in virtual space is sensitive to gender but not activity-passivity or mode of interaction.

CyberPsychology \& Behavior, 7(4), 451-457. https://doi.org/10.1089/cpb.2004.7.451

Fraillon, J., Ainley, J., Schulz, W., Friedman, T., \& Duckworth, D. (2020). Preparing for life in a digital world. Springer.

Freeman, J. L., Caldwell, P. H., Bennett, P. A., \& Scott, K. M. (2018). How adolescents search for and appraise online health information: A systematic review. The Journal of Pediatrics, 195, 244-255. https://doi.org/10.1016/j.jpeds.2017.11.031

Gossen, T., Höbel, J., \& Nürnberger, A. (2014). Usability and perception of young users and adults on targeted web search engines. IIiX '14: Proceedings of the 5th Information Interaction in Context Symposium, 18-27. https://doi.org/10.1145/2637002.2637007

Gossen, T., Low, T., \& Nürnberger, A. (2011). What are the real differences of children's and adults' web search. Proceedings of the 34th International ACM SIGIR Conference on Research and Development in Information Retrieval, 1115-1116. https://doi.org/https://dx.doi.org/10.1145/2009916.2010076

Gray, N. J., Klein, J. D., Cantrill, J. A., \& Noyce, P. R. (2002). Adolescent girls' use of the internet for health information: Issues beyond access. Journal of Medical Systems, 26(6), 545-553. https://doi.org/10.1023/A:1020296710179 
Gray, N. J., Klein, J. D., Noyce, P. R., Sesselberg, T. S., \& Cantrill, J. A. (2005). The internet: A window on adolescent health literacy. Journal of Adolescent Health, 37(3), 243.E1-243.E7. https://doi.org/10.1016/j.jadohealth.2004.08.023

Greene, J. A., Copeland, D. Z., Deekens, V. M., \& Seung, B. Y. (2018). Beyond knowledge: Examining digital literacy's role in the acquisition of understanding in science. Computers \& Education, 117, 141-159. https://doi.org/10.1016/j.compedu.2017.10.003

Greene, J. A., Seung, B. Y., \& Copeland, D. Z. (2014). Measuring critical components of digital literacy and their relationships with learning. Computers $\&$ Education, 76, 55-69. https://doi.org/10.1016/j.compedu.2014.03.008

Gui, M., \& Argentin, G. (2011). Digital skills of internet natives: Different forms of digital literacy in a random sample of northern italian high school students. New Media 6 Society, 13(6), 963-980. https://doi.org/10.1177/1461444810389751

Gureckis, T. M., \& Markant, D. B. (2012). Self-directed learning: A cognitive and computational perspective. Perspectives on Psychological Science, 7(5), 464-481. https://doi.org/10.1177/1745691612454304

Gwizdka, J., \& Bilal, D. (2017). Analysis of children's queries and click behavior on ranked results and their thought processes in google search. Proceedings of the 2017 conference on conference human information interaction and retrieval, 377-380. https://dl.acm.org/doi/pdf/10.1145/3020165.3022157

Hailikari, T., Katajavuori, N., \& Lindblom-Ylanne, S. (2008). The relevance of prior knowledge in learning and instructional design. American Journal of Pharmaceutical Education, 72(5). https://doi.org/10.5688/aj7205113

Hargittai, E. (2010). Digital na(t)ives? variation in internet skills and uses among members of the "net generation." Sociological Inquiry, 80(1), 92-113. https://doi.org/10.1111/j.1475-682X.2009.00317.x 
Hatlevik, O. E., Throndsen, I., Loi, M., \& Gudmundsdottir, G. B. (2018). Students' ict self-efficacy and computer and information literacy: Determinants and relationships. Computers \& Education, 118, 107-119. https://doi.org/10.1016/j.compedu.2017.11.011

Hautala, J., Kiili, C., Kammerer, Y., Loberg, O., Hokkanen, S., \& Leppänen, P. H. (2018). Sixth graders' evaluation strategies when reading internet search results: An eye-tracking study. Behaviour \& Information Technology, 37(8), 761-773. https://doi.org/doi:10.1080/0144929x.2018.1477992

Hegarty, N., \& Carbery, A. (2010). Piloting a dedicated information literacy programme for nursing students at waterford institute of technology libraries. Library Review, 59(8), 606-614. https://doi.org/10.1108/00242531011073137

Hembrooke, H. A., Granka, L. A., Gay, G. K., \& Liddy, E. D. (2005). The effects of expertise and feedback on search term selection and subsequent learning. Journal of the American Society for Information Science and Technology, 56 (8), 861-871. https://doi.org/10.1002/asi.20180

Henderson, E. M., Keogh, E., Rosser, B. A., \& Eccleston, C. (2013). Searching the internet for help with pain: Adolescent search, coping, and medication behaviour. British Journal of Health Psychology, 18(1), 218-232. https://doi.org/10.1111/bjhp.12005

Jiménez-Pernett, J., de Labry-Lima, A. O., Bermúdez-Tamayo, C., García-Gutiérrez, J. F., \& del Carmen Salcedo-Sánchez, M. (2010). Use of the internet as a source of health information by spanish adolescents. BMC Medical Informatics and Decision Making, 10(1), Article 6. https://doi.org/10.1186/1472-6947-10-6

Johnston, B., \& Webber, S. (2003). Information literacy in higher education: A review and case study. Studies in Higher Education, 28(3), 335-352. https://doi.org/10.1080/03075070309295

Jones, B., \& Flannigan, S. L. (2006). Connecting the digital dots: Literacy of the 21st century. Educause Quarterly, 29(2), 8-10. 
Jones, R. K., \& Biddlecom, A. E. (2011a). Is the internet filling the sexual health information gap for teens? an exploratory study. Journal of Health Communication, 16(2), 112-123. https://doi.org/10.1080/10810730.2010.535112

Jones, R. K., \& Biddlecom, A. E. (2011b). The more things change. . . The relative importance of the internet as a source of contraceptive information for teens. Sexuality Research and Social Policy, 8(1), 27-37. https://doi.org/http://doi.org/10.1007/s13178-0110039-0

Juslin, P., Winman, A., \& Hansson, P. (2007). The naïve intuitive statistician: A naïve sampling model of intuitive confidence intervals. Psychological Review, 114(3), 678-703. https://doi.org/10.1037/0033-295X.114.3.678

Kammerer, Y., \& Gerjets, P. (2014). The role of search result position and source trustworthiness in the selection of web search results when using a list or a grid interface. International Journal of Human-Computer Interaction, 30(3), 177-191. https://doi.org/10.1080/10447318.2013.846790

Kammerer, Y., Gottschling, S., \& Bråten, I. (2021). The role of internet-specific justification beliefs in source evaluation and corroboration during web search on an unsettled socio-scientific issue. Journal of Educational Computing Research, 59(2), 342-378. https://doi.org/10.1177/0735633120952731

Kavšek, T., Peklaj, C., \& Žugelj, U. (2016). Information literacy training evaluation: The case of first year psychology students. The Journal of Academic Librarianship, 42(4), 293-299. https://doi.org/10.1016/j.acalib.2016.06.008

Keehner, M., Hegarty, M., Cohen, C., Khooshabeh, P., \& Montello, D. R. (2008). Spatial reasoning with external visualizations: What matters is what you see, not whether you interact. Cognitive science, 32(7), 1099-1132. https://doi.org/10.1080/03640210801898177 
Kelly, D., \& Cool, C. (2002). The effects of topic familiarity on information search behavior. Proceedings of the 2nd ACM/IEEE-CS joint conference on Digital libraries, 74-75. https://doi.org/10.1145/544220.544232

Kluzer, S., \& Priego, L. P. (2018). Digcomp into action: Get inspired, make it happen. a user guide to the european digital competence framework (Technical report). Joint Research Centre; S. Carretero Gomez, Y. Punie, R. Vuorikari, M. Cabrera Giraldez,\& W.Okeeffe, Eds. Publications Office of the European Union. https://doi.org/10.2760/112945

Kobayashi, T., Misue, K., Shizuki, B., \& Tanaka, J. (2006). Information gathering support interface by the overview presentation of web search results. Proceedings of the 2006 Asia-Pacific Symposium on Information Visualisation-Volume 60, 103-108.

Lai, C.-L., Hwang, G.-J., \& Tu, Y.-H. (2018). The effects of computer-supported self-regulation in science inquiry on learning outcomes, learning processes, and self-efficacy. Educational Technology Research and Development, 66(4), 863-892. https://doi.org/10.1007/s11423-018-9585-y

Large, A., Beheshti, J., \& Rahman, T. (2002). Gender differences in collaborative web searching behavior: An elementary school study. Information Processing 86 Management, 38(3), 427-443. https://doi.org/10.1016/S0306-4573(01)00034-6

Lenhart, A., Madden, M., Rankin Macgill, A., \& Smith, A. (2007). Teens and social media: The use of social media gains a greater foothold in teen life as they embrace the conversational nature of interactive online media. (tech. rep.). Pew Research Center, Washington, DC. Pew Internet \& American Life Project Summary of Findings, Washington, DC.

Lewandowski, D., \& Kammerer, Y. (2020). Factors influencing viewing behaviour on search engine results pages: A review of eye-tracking research. Behaviour $\&$ Information Technology, O(0), 1-31. https://doi.org/10.1080/0144929X.2020.1761450 
Liu, C., Gwizdka, J., Liu, J., Xu, T., \& Belkin, N. J. (2010). Analysis and evaluation of query reformulations in different task types. Proceedings of the American Society for Information Science and Technology, 47(1), 1-9.

https://doi.org/10.1002/meet.14504701214

Liu, C., Ward, J., \& Markall, H. (2007). The role of active exploration of 3d face stimuli on recognition memory of facial information. Journal of Experimental Psychology:

Human Perception and Performance, 33(4), 895-904.

https://doi.org/10.1037/0096-1523.33.4.895

Livingstone, S. (2004). Media literacy and the challenge of new information and communication technologies. The Communication Review, 7(1), 3-14. https://doi.org/10.1080/10714420490280152

Maitz, E., Maitz, K., Sendlhofer, G., Wolfsberger, C., Mautner, S., Kamolz, L.-P., \& Gasteiger-Klicpera, B. (2020). Internet-based health information-seeking behavior of students aged 12 to 14 years: Mixed methods study. Journal of Medical Internet Research, 22(5), Article e16281. https://doi.org/10.2196/16281

Malbon, K. M., Ojong, T., \& Nucci-Sack, A. (2012). 20. access to sexual health education and care for adolescents: Using technology. Journal of Adolescent Health, 50(2), S24-S25. https://doi.org/10.1016/j.jpeds.2020.02.074

Marchak, F. M., \& Zulager, D. D. (1992). The effectiveness of dynamic graphics in revealing structure in multivariate data. Behavior Research Methods, Instruments, 63 Computers, 24(2), 253-257. https://doi.org/10.3758/BF03203503

Markant, D., DuBrow, S., Davachi, L., \& Gureckis, T. M. (2014). Deconstructing the effect of self-directed study on episodic memory. Memory $\&$ Cognition, 42(8), 1211-1224. https://doi.org/10.3758/s13421-014-0435-9

Markant, D., \& Gureckis, T. M. (2014). Is it better to select or to receive? learning via active and passive hypothesis testing. Journal of Experimental Psychology: General, 143(1), 94-122. https://doi.org/10.1037/a0032108 
Markant, D., Ruggeri, A., Gureckis, T. M., \& Xu, F. (2016). Enhanced memory as a common effect of active learning. Mind, Brain, and Education, 10(3), 142-152. https://doi.org/10.1111/mbe.12117

Mason, L., Boldrin, A., \& Ariasi, N. (2010). Epistemic metacognition in context: Evaluating and learning online information. Metacognition and Learning, 5(1), 67-90. https://doi.org/10.1007/s11409-009-9048-2

McGrew, S., Breakstone, J., Ortega, T., Smith, M., \& Wineburg, S. (2018). Can students evaluate online sources? learning from assessments of civic online reasoning. Theory 8 Research in Social Education, 46(2), 165-193. https://doi.org/10.1080/00933104.2017.1416320

Mills, C. M. (2013). Knowing when to doubt: Developing a critical stance when learning from others. Developmental Psychology, 49(3), 404-418. https://doi.org/10.1037/a0029500

Munn, J., \& Small, J. (2017). What is the best way to develop information literacy and academic skills of first year health science students? a systematic review. Evidence Based Library and Information Practice, 12(3), 56-94. https://doi.org/10.18438/B8QS9M

Murty, V. P., DuBrow, S., \& Davachi, L. (2015). The simple act of choosing influences declarative memory. Journal of Neuroscience, 35(16), 6255-6264. https://doi.org/10.1523/JNEUROSCI.4181-14.2015

National Science Board. (2012). Science and technology: Public attitudes and understanding (Technical report). National Science Foundation. Science; Engineering Indicators, National Science Foundation, Arlington, VA.

Ng, W. (2012). Can we teach digital natives digital literacy? Computers \& Education, 59(3), 1065-1078. https://doi.org/10.1016/j.compedu.2012.04.016

Palmquist, R. A., \& Kim, K.-S. (2000). Cognitive style and on-line database search experience as predictors of web search performance. Journal of the American Society 
for Information Science, 51(6), 558-566.

https://doi.org/10.1002/(SICI)1097-4571(2000)51:6<558::AID-ASI7>3.0.CO;2-9

Partridge, E., McGovern, M. G., Yung, A., \& Kidd, C. (2015). Young children's

self-directed information gathering on touchscreens. Proceedings of the 37th Annual Conference of the Cognitive Science Society, 1835-1840.

Pezzulo, G., Cartoni, E., Rigoli, F., Pio-Lopez, L., \& Friston, K. (2016). Active inference, epistemic value, and vicarious trial and error. Learning \&5 Memory, 23(7), 322-338. https://doi.org/10.1101/lm.041780.116

Plancher, G., Barra, J., Orriols, E., \& Piolino, P. (2013). The influence of action on episodic memory: A virtual reality study. Quarterly Journal of Experimental Psychology, 66 (5), 895-909. https://doi.org/10.1080/17470218.2012.722657

Porat, E., Blau, I., \& Barak, A. (2018). Measuring digital literacies: Junior high-school students' perceived competencies versus actual performance. Computers $\mathbb{E}$ Education, 126, 23-36. https://doi.org/10.1016/j.compedu.2018.06.030

Rainie, L., Keeter, S., \& Perrin, A. (2019). Trust and distrust in america (Technical report). Pew Research Center.

Rennis, L., McNamara, G., Seidel, E., \& Shneyderman, Y. (2015). Google it!: Urban community college students' use of the internet to obtain self-care and personal health information. College Student Journal, 49(3), 414-426.

Richardson, B. L., Wuillemin, D. B., \& MacKintosh, G. J. (1981). Can passive touch be better than active touch? a comparison of active and passive tactile maze learning. British Journal of Psychology, 72(3), 353-362. https://doi.org/10.1111/j.2044-8295.1981.tb02194.x

Robards, F., Sanci, L., Steinbeck, K., Jan, S., Hawke, C., Kong, M., et al. (2017). Access 3: Young people's healthcare journeys, preliminary report. Sydney (Australia): Department of General Practice, Sydney Medical School Westmead, The University 
of Sydney in partnership with the Australian Centre for Public and Population Health Research, Faculty of Health, The University of Technology Sydney.

Roy, M., \& Chi, M. T. (2003). Gender differences in patterns of searching the web. Journal of Educational Computing Research, 29(3), 335-348. https://doi.org/10.2190/7BR8-VXA0-07A7-8AVN

Ruggeri, A., Markant, D. B., Gureckis, T. M., Bretzke, M., \& Xu, F. (2019). Memory enhancements from active control of learning emerge across development. Cognition, 186, 82-94. https://doi.org/10.1016/j.cognition.2019.01.010

Saunders, L., Severyn, J., \& Caron, J. (2017). Don't they teach that in high school? examining the high school to college information literacy gap. Library Information Science Research, 39(4), 276-283. https://doi.org/10.1016/j.lisr.2017.11.006

Schwartz, S. H. (1966). Trial-by-trial analysis of processes in simple and disjunctive concept-attainment tasks. Journal of Experimental Psychology, 72(3), 456-465. https://doi.org/10.1037/h0023652

Selkie, E. M., Benson, M., \& Moreno, M. (2011). Adolescents' views regarding uses of social networking websites and text messaging for adolescent sexual health education. American Journal of Health Education, 42(4), 205-212. https://doi.org/10.1080/19325037.2011.10599189

Sharit, J., Hernández, M. A., Czaja, S. J., \& Pirolli, P. (2008). Investigating the roles of knowledge and cognitive abilities in older adult information seeking on the web. ACM Transactions on Computer-Human Interaction (TOCHI), 15(1), 1-25. https://doi.org/10.1145/1352782.1352785

Shifflet-Chila, E. D., Harold, R. D., Fitton, V. A., \& Ahmedani, B. K. (2016). Adolescent and family development: Autonomy and identity in the digital age. Children and Youth Services Review, 70, 364-368. https://doi.org/10.1016/j.childyouth.2016.10.005 
Skinner, H., Biscope, S., Poland, B., \& Goldberg, E. (2003). How adolescents use technology for health information: Implications for health professionals from focus group studies. Journal of Medical Internet Research, 5(4), Article e32. https://doi.org/10.2196/jmir.5.4.e32

Skopelja, E. N., Whipple, E. C., \& Richwine, P. (2008). Reaching and teaching teens: Adolescent health literacy and the internet. Journal of Consumer Health on the Internet, 12(2), 105-118. https://doi.org/10.1080/15398280802121406

Smahel, D., Machackova, H., Mascheroni, G., Dedkova, L., Staksrud, E., Ólafsson, K., Livingstone, S., \& Hasebrink, U. (2020). Survey results from 19 countries (Technical report). EU Kids Online. https://doi.org/10.21953/lse.47fdeqj01ofo

Sobel, D. M., \& Kushnir, T. (2006). The importance of decision making in causal learning from interventions. Memory \& Cognition, 34(2), 411-419. https://doi.org/10.3758/BF03193418

Sobel, D. M., \& Kushnir, T. (2013). Knowledge matters: How children evaluate the reliability of testimony as a process of rational inference. Psychological Review, 120(4), 779-797. https://doi.org/10.1037/a0034191

Steyvers, M., Tenenbaum, J. B., Wagenmakers, E.-J., \& Blum, B. (2003). Inferring causal networks from observations and interventions. Cognitive Science, 27(3), 453-489. https://doi.org/10.1016/S0364-0213(03)00010-7

Storksdieck, M. (2016). Critical information literacy as core skill for lifelong stem learning in the 21st century: Reflections on the desirability and feasibility for widespread science media education. Cultural Studies of Science Education, 11(1), 167-182. https://doi.org/10.1007/s11422-015-9714-4

Strom, P., Strom, R., Wing, C., \& Beckert, T. (2009). Adolescent learning and the internet: Implications for school leadership and student engagement in learning. NASSP Bulletin, 93(2), 111-121. https://doi.org/10.1177/0192636509340436 
Taylor, H. A., Naylor, S. J., \& Chechile, N. A. (1999). Goal-specific influences on the representation of spatial perspective. Memory \& Cognition, 27(2), 309-319. https://doi.org/10.3758/BF03211414

Thatcher, A. (2008). Web search strategies: The influence of web experience and task type. Information Processing 83 Management, 44(3), 1308-1329. https://doi.org/10.1016/j.ipm.2007.09.004

Toms, E. G., \& Latter, C. (2007). How consumers search for health information. Health Informatics Journal, 13(3), 223-235. https://doi.org/10.1177/1460458207079901

Tu, Y.-W., Shih, M., \& Tsai, C.-C. (2008a). Eighth graders' web searching strategies and outcomes: The role of task types, web experiences and epistemological beliefs. Computers \& Education, 51(3), 1142-1153. https://doi.org/10.1016/j.compedu.2007.11.003

Tu, Y.-W., Shih, M., \& Tsai, C.-C. (2008b). Eighth graders' web searching strategies and outcomes: The role of task types, web experiences and epistemological beliefs. Computers \& Education, 51(3), 1142-1153. https://doi.org/10.1016/j.compedu.2007.11.003

Voss, J. L., Warren, D. E., Gonsalves, B. D., Federmeier, K. D., Tranel, D., \& Cohen, N. J. (2011). Spontaneous revisitation during visual exploration as a link among strategic behavior, learning, and the hippocampus. Proceedings of the National Academy of Sciences of the United States of America, 108(31), E402-E409. https://doi.org/10.1073/pnas.1100225108

Walhout, J., Brand-Gruwel, S., Jarodzka, H., van Dijk, M., de Groot, R., \& Kirschner, P. A. (2015). Learning and navigating in hypertext: Navigational support by hierarchical menu or tag cloud? Computers in Human Behavior, 46, 218-227. https://doi.org/https://doi.org/10.1016/j.chb.2015.01.025

Walhout, J., Oomen, P., Jarodzka, H., \& Brand-Gruwel, S. (2017). Effects of task complexity on online search behavior of adolescents. Journal of the Association for 
Information Science and Technology, 68(6), 1449-1461.

https://doi.org/10.1002/asi.23782

Wallace, M. C., Shorten, A., \& Crookes, P. A. (2000). Teaching information literacy skills: An evaluation. Nurse Education Today, 20(6), 485-489.

https://doi.org/10.1054/nedt.1999.0439

Wegener, D. R. (2018). Information literacy: Diagnostics, interventions, and assessments. Singapore Journal of Library \& Information Management, 47, 102-113.

White, R. W., Dumais, S. T., \& Teevan, J. (2009). Characterizing the influence of domain expertise on web search behavior. Proceedings of the Second ACM International Conference on Web Search and Data Mining, 132-141. https://doi.org/10.1145/1498759.1498819

Wildemuth, B. M. (2004). The effects of domain knowledge on search tactic formulation. Journal of the American Society for Information Science and Technology, 55(3), 246-258. https://doi.org/10.1002/asi.10367

Wilson, P. N. (1999). Active exploration of a virtual environment does not promote orientation or memory for objects. Environment and Behavior, 31(6), 752-763. https://doi.org/10.1177/00139169921972335

Wilson, P. N., \& Peruch, P. (2002). The influence of interactivity and attention on spatial learning in a desk-top virtual environment. Cahiers de Psychologie Cognitive, 21(6), 601-633.

Zlatkin-Troitschanskaia, O., Beck, K., Fischer, J., Braunheim, D., Schmidt, S., \& Shavelson, R. J. (2020). The role of students' beliefs when critically reasoning from multiple contradictory sources of information in performance assessments. Frontiers in psychology, 11. https://doi.org/10.3389/fpsyg.2020.02192 


\section{Appendix \\ Complete study procedures}

\section{A.1. Instructions}

Instructions given to participants before the active and yoked research phase on each topic. Target keywords are written in bold.

\section{1) Read the following text carefully:}

(Nitrates). "I am Sue, and I am 22 years old. I was at the grocery store yesterday and I noticed that on some drinking water bottles it is specified in capital letters that they contain low levels of nitrates. I have asked around and apparently, many people seem to think that the nitrates contained in some water can cause cancer. I am really confused because I wasn't aware of this risk before, and I wonder whether there is reliable scientific evidence confirming this claim. Should I stop drinking mineral water containing nitrates or is this not really harmful?"

(Aluminum). "I am Bea, and I am 22 years old. I was at the drugstore yesterday and I noticed that on many deodorants it is specified in capital letters that they do not contain aluminum. I have asked around and apparently, many people seem to think that using deodorants containing aluminum can cause breast cancer. I am really confused because I was not aware of this risk before, and I wonder whether there is reliable scientific evidence confirming this claim. Should I stop using deodorants containing aluminum or is this not really harmful?"

\section{2) Now follow the instructions below:}

You have 10 minutes to search [active condition] - You will watch a video of the previous participant searching [yoked condition] — for accurate information about this topic on Google in order to give an informed suggestion to Sue/Bea. You can take notes. Your goal is to come up with a suggestion and a justification for this suggestion, and then 
answer some questions about this topic. Try to be as exhaustive and accurate as possible. An expert in the field will judge the accuracy and completeness of all justifications and will choose the most accurate. The best justification will be rewarded with a 25-euro Amazon voucher.

\section{A.2. Assessments}

\section{Table A1}

Source reliability. English translation of the answers presented on the 5-item multiple-choice questionnaire used to assess participants' intuitions about the characteristics that make a website reliable or unreliable. Participants could select multiple items

\section{Why was this source reliable? Why was this source unreliable?}

It was clear

It provided scientific evidence

It was familiar

It was suggested by Google

It was cool
It was not clear

It provided no scientific evidence

It was not familiar

It was not suggested by Google

It was not cool 


\section{Table A2}

Source reliability. Original links to web pages provided by participants for the source reliability assessment, categorized by source type.

\begin{tabular}{ll} 
Source type & Link \\
\hline NGO & altroconsumo.it \\
IGO & salute.gov.it \\
Commercial & nivea.it \\
Blog & naturalmentemamma.it \\
Wikipedia & wikipedia.it \\
Magazine & tio.ch \\
Scientific journal & academic.oup.com
\end{tabular}

Note. $\mathrm{NGO}=$ nongovernmental organization; IGO $=$ international governmental organization.

Magazines and scientific journals were never provided as the most reliable web sources found but were visited by two participants during the active search. 


\section{Table A3}

Factual knowledge. English translations of the forced-choice questionnaire used to assess participants' factual knowledge about each substance (nitrates and aluminum) and their relatedness to cancer. Correct answers are written in italics.

\section{Nitrates}

Do all types of water contain nitrates?

1) Yes, both tap and bottled water contain nitrates

2) No, only bottled still water contains nitrates

3) No, only bottled sparkling water contains nitrates

Why have some scientists hypothesized that nitrates in drinking water might cause cancer?

1) Because nitrites (NO2-) can be converted into nitrates (NO3-) within our organism and can act

as precursors of N-nitroso compounds, which are considered extremely carcinogenic

2) Because nitrates (NO3-) react within our organism to form $N$-nitroso compounds, which are able to modify the molecular structure of the cell and thus cause abnormal cell growth

3) Because nitrates (NO3-) can be converted into nitrites (NO2-) within our organism

and can act as precursors of N-nitroso compounds, which are considered extremely carcinogenic

According to Italian law, the amount of nitrates in drinking water must be below...

1) $40 \mathrm{mg} / \mathrm{L}$

2) $50 \mathrm{mg} / \mathrm{L}$

3) $40 \mathrm{mg} / \mathrm{L}$

\section{Aluminum}

Do all deodorants contain aluminum?

1) Every commercial deodorant contains aluminum

2) Aluminum is contained only in the spray kind of deodorant and not in roll-ons

3) Only antiperspirant deodorants contain aluminum

Why have some scientists assumed that aluminum-containing deodorants can cause breast cancer?

1) Because aluminum is absorbed by the skin and could have estrogen-like effects, thus promoting breast cancer

2) Because aluminum contains estrogen, which when absorbed by the skin can promote carcinogenic cells' growth

3) Because when aluminum is absorbed by the skin it can release some toxins that can promote breast cancer

Why do some deodorants contain aluminum?

1) Because it covers the stinky chemicals excreted by sweat

2) Because it can plug up sweat glands, thus stopping us from sweating

3) Because it kills the bacteria producing the stinky chemicals 